\title{
Sinonasal Surgeries in a Tertiary Health Care Institution in a Developing Country, Nigeria
}

\author{
Waheed Atilade Adegbiji* \\ ENT Department, Ekiti State University Teaching Hospital, Nigeria
}

*Corresponding author: Waheed Atilade Adegbij, ENT Department, Ekiti State University Teaching Hospital, Ado Ekiti, Nigeria

\begin{abstract}
Background: Sinonasal diseases usually required surgical management. There is increasing cases of poorly treatment by nonspecialist. This study aimed at determining sociodemographic features, indications, complication and outcome of sinonasal surgeries

Materials and methods: This was a retrospective study of patients that had sinonasal procedures in our tertiary health care facility. The data collected were collated and analyzed using Statistical Package for Social Sciences (SPSS) version 18.0.

Results: The proportion of sinonasal procedures among the patients was $31.6 \%$. There were $58.8 \%$ males with male to female ratio of 1.5:1 Major presenting complaints was 57.3\% nasal blockage and 52.8\% catarrh/epistaxis. Common clinical findings were rhinorrhea and reduced nasal patency in $69.4 \%$ and $48.8 \%$ respectively. Sinonasal procedures in unilateral nasal cavity was $52.2 \%$ while right nasal cavity occurred in $29.6 \%$. Outpatient clinic procedures was $66.7 \%$, elective procedures accounted for $60.5 \%$ and major procedures accounted for $29.3 \%$. masses is the commonest CT Scan findings in $20.3 \%$ followed by sinuses in $15.6 \%$. Main diagnosis was 39.9\% rhinosinusitis, 38.3\% foreign body impaction and $10.8 \%$ nasal polyps. Common sinonasal procedures were $38.3 \%$ nasal foreign body removal, $10.8 \%$ polypectomy, $9.8 \%$ antral washout and 9.3\% nasal packing. Main complication of sinonasal procedures were wound infection in $2.9 \%$ and recurrence in $2.6 \%$. There was $76.2 \%$ patient's satisfaction with the sinonasal surgeries.
\end{abstract}

Conclusion: Sinonasal surgery is common in all age group. Presentation were most late, complicated and advanced. It mostly presented as clinic and elective procedures in this study.

Keywords: Rhinologist; sinonasal surgeries; nasal diseases; sino nasal diseases

\section{Introduction}

Sino nasal surgery is an art of surgical treatment of the nose and para-nasal sinuses pathology by either otorhinolaryngologic or Rhinologist [1,2]. Sino nasal diseases are on the increase due increase in industrialisation and technology [3-5]. There is also increase in sociomedical interaction and cosmetic consciousness about nose worldwide [5]. All these has led to growing rhinology subspecialty demands. Nose occupied the strategic position in the middle third of the face [6-8]. It is the outermost and uppermost conduit of the respiratory tract and prone to all forms of environmental hazard. This ranges from congenital to acquired diseases $[3,4]$. Various types of acquired nasal diseases includes traumatic, inflammatory, neoplastic, metabolic and systemic diseases with nasal manifestation [3,4]. Sinonasal diseases may also be primary or secondary to diseases from other head and neck organs which includes eye/orbit, dental apparatus, brain, cranial nerves and other intracranial structures [9-11]. These are managed by different forms of surgical approach and adjunct medical treatment. Clinical presentation of sinonasal disorders and other related diseases such as rhinosinusitis, sin nasal tumour, nasal polyps, dental diseases, lacrimal disorders, pituitary tumours, sin nasal cerebrospinal fluid rhinorrhea, and anterior skull base tumours presented to family physician, casualty officers, neurosurgeons, and ophthalmologists and subsequently referred to otorhinolaryngologic [12-14]. Pattern of clinical features of sinonasal diseases are nasal discharge, nasal blockage, nasal mass, bout of sneezing, headache, fever and facial asymmetry $[13,14]$. Other related symptoms depends on the primary source of sinonasal diseases which includes ocular symptoms, orodental 
symptoms and central nervous system symptoms. Radiological imaging inform of computerised tomography scan is required to rule out the extent of the tumour and bony destruction. Sinonasal endoscopy for diagnosis and determined to tumour origin with its extent is also an important investigation.

Majority of sinonasal surgery may be done in by otorhinolaryngologist or rhinologist alone or in team in collaboration with ophthalmologist, neurosurgeon, plastic and oral and maxillofacial surgeon. The approaches may either intranasal and extra nasal depending on the site and extent of the pathology [15-16]. Non-invasive procedures such as functional endoscopic sinus surgery is a newer surgical technique $[2,9]$. It is not a common surgical intervention in low income country like other surgical procedures but a commonplace in the developed countries. Sinonasal surgery in most developing countries has been hampered by the dearth of otorhinolaryngologic and rhinologist. There is also inadequacy of proper diagnostic tools and therapeutic facilities in developing countries compare to developed world. There is a paucity of publication documents on the pattern of sinonasal surgeries in developing countries. The knowledge from the documentation of sinonasal surgeries in our environment will help draw attention of the appropriate authorities to the challenges in the surgical practice. This will serve as bases to develop and form policy on sinonasal surgery improvement. This study aimed determining sociodemographic features, types, indications, limitation, complication and outcome of sinonasal surgeries in a tertiary health care institution of a developing country.

\section{Materials and Methods}

This was a retrospective study of all patients that had sinonasal surgeries done in Ear, Nose and Throat department of Ekiti state university teaching hospital Ado Ekiti, Nigeria. The study was carried out over a period five years (between October 2014 to September 2019). Data for this study was obtained from the hospital medical record department, ENT clinic operation booking register for both minor and major surgery and theatre operation register. The case notes of all the eligible patients were retrieved from the medical record department. Detailed data on sociodemographic features were obtained from the patient's case note. Data of patient on clinical features, diagnosis, and indication for procedures, and type of procedures, complications, and patient's satisfaction with the outcome of the procedures were obtained and documented. Inclusion criteria were all the patients that had sinonasal procedures in the department during the study period. Exclusion criteria were those patients who were not operated. Also, patients with incomplete clinical data on this study or those with missing case notes. All the obtained data were collated, documented and statistically analysed using SPSS version 18.0. The data were then expressed by descriptive statistics in frequency tables, percentage, bar chart and pie chart.

\section{Results}

The total number of patients seen during the period of study was 7,916 out of which a total of 1965 (24.8\%) had sinonasal diseases and 621 had sinonasal procedures done given prevalence of $31.6 \%$.
In this study, the peak age groups were at the extreme ages of (1-10) years with highest number of procedures in 218 (35.1\%). This is illustrated in Table 1. Gender distribution were 365 (58.8\%) males and $256(41.2 \%)$ females with male to female ratio of 1.5:1. Urban dwellers 341 (54.9\%) were commoner than rural dwellers 280 (45.1\%). Christians faith occurred in 547 (88.1\%) while Muslims faith occurred in 74 (11.9\%). Main patient/parent education level were 182 (29.3\%) primary and 173 (27.9\%) secondary. Parent/ patient occupation distribution were mainly student/apprentice, civil servants and business in 277 (44.6\%), 138 (22.2\%) and 89 (14.3\%) respectively. This is showed in Table 2. Major presenting complaints was nasal blockage in 356 (57.3\%) followed by catarrh/ epistaxis, objects in the nose and bout of sneezing in 328 (52.8\%), 246 (39.6\%) and 228 (36.7\%). Common clinical findings were rhinorrhea, reduced nasal patency, foreign body impaction and sinonasal masses in 431 (69.4\%), 303 (48.8\%), 238 (38.3\%) and $100(16.1 \%)$ respectively. As demonstrated in Table 3.

Table 1: Age group distribution of the patients.

\begin{tabular}{|c|c|c|}
\hline Age (years) & Number & Percentage (\%) \\
\hline 10-Jan & 218 & 35.1 \\
\hline $20-$ Nov & 123 & 19.8 \\
\hline $21-30$ & 64 & 10.3 \\
\hline $31-40$ & 88 & 14.2 \\
\hline $41-50$ & 49 & 7.9 \\
\hline $51-60$ & 41 & 6.6 \\
\hline$\geq 61$ & 38 & 6.1 \\
\hline & 621 & 100 \\
\hline
\end{tabular}

Table 2: Sociodemographic features of the patients.

\begin{tabular}{|c|c|c|}
\hline Sociodemographic features & Number & Percentage (\%) \\
\hline \multicolumn{3}{|c|}{ Sex } \\
\hline Male & 365 & 58.8 \\
\hline Female & 256 & 41.2 \\
\hline \multicolumn{3}{|c|}{ Dwelling } \\
\hline Urban & 341 & 54.9 \\
\hline Rural & 280 & 45.1 \\
\hline \multicolumn{3}{|c|}{ Religion } \\
\hline Christian & 547 & 88.1 \\
\hline Muslim & 74 & 11.9 \\
\hline \multicolumn{3}{|c|}{ Education level } \\
\hline Nil formal & 165 & 26.6 \\
\hline Primary & 182 & 29.3 \\
\hline Secondary & 173 & 27.9 \\
\hline Post-secondary & 101 & 16.3 \\
\hline \multicolumn{3}{|c|}{ Parent/patient Occupation } \\
\hline Students/apprentice & 277 & 44.6 \\
\hline Business & 89 & 14.3 \\
\hline Artisan & 83 & 13.4 \\
\hline Civil servant & 138 & 22.2 \\
\hline Farming & 34 & 5.5 \\
\hline
\end{tabular}


Table 3: Main clinical features among patients.

\begin{tabular}{|c|c|c|}
\hline \multicolumn{2}{|c|}{ Symptoms } & Percentage (\%) \\
\hline Catarrhical features & 328 & 52.8 \\
\hline Loss of smell/bad smell & 73 & 11.8 \\
\hline Nasal blockage & 356 & 57.3 \\
\hline Object in the nose & 246 & 39.6 \\
\hline Bout of sneezing & 228 & 36.7 \\
\hline Nasal mass & 86 & 13.8 \\
\hline Headache & 84 & 13.5 \\
\hline Laceration/injuries & Signs & 5.2 \\
\hline Reduced nasal patency & 32 & 48.8 \\
\hline Rhinorrhea & 431 & 69.4 \\
\hline Facial asymmetry & 32 & 5.2 \\
\hline Inferior turbinate enlargement & 51 & 38.3 \\
\hline Foreign body impaction & 238 & 16.1 \\
\hline Sinonasal masses & 100 & \\
\hline
\end{tabular}

Sinonasal procedures was commoner in unilateral nasal cavity in 324 (52.2\%) than bilateral nasal cavity in 297 (47.8\%). Right nasal cavity and left nasal cavity procedures occurred in 184 (29.6\%) and $140(22.5 \%)$ respectively. As illustrated in Figure 1. Majority of the procedures in 414 (66.7\%) were performed in the outpatient clinic and minority in 207 (33.3\%) were performed in the theatre. Theatre procedures were classified into minor, intermediate and major procedures which accounted for $8(1.3 \%), 17(2.7 \%)$ and $182(29.3 \%)$ respectively. All sinonasal procedures were divided into elective and emergency procedures which accounted for 376 $(60.5 \%)$ and 245 (39.5\%) respectively. This is demonstrated in Table 4. Intranasal masses is the commonest CT Scan findings in 126 (20.3\%). CT Scan findings in the sinuses accounted for 97 (15.6\%) with maxillary and ethmoid sinuses accounted for $52(8.4 \%)$ and 39 (6.3\%) respectively. Common extension of the sinonasal pathology in this study were orbital extension and intracranial extension in $59(9.5 \%)$ and $21(3.4 \%)$ respectively. This is illustrated in
(Figure 2). Main diagnosis and indication for sinonasal procedures in this study were rhinosinusitis in 248 (39.9\%), nasal polyps in 67 (10.8\%), sinonasal injuries in 29 (4.7\%) and foreign body impaction in 238 (38.3\%). Less common diagnosis and indications were nasolabial cyst, frontoethmoidal mucocele, and fungal mass in $2(0.3 \%), 3(0.5 \%)$ and $4(0.6 \%)$ respectively. This is showed in (Table 5). Commonest sinonasal interventional procedures in patients with sinonasal diseases in this study was 238 (38.3\%) foreign body removal from the nose. Removal without anaesthesia and under general anaesthesia were 226 (36.4\%) and 12 (1.9\%) respectively. Other main sinonasal surgeries were polypectomy, antral washout (lavage), nasal packing, partial turbinectomy, nasal toileting/clearance and intranasal antrostomy in 67 (10.8\%), 61 (9.8\%), 58 (9.3\%), 51 (8.2\%), 46 (7.4\%) and 44 (7.1\%) respectively. Intranasal polypectomy occurred in $59(9.5 \%)$ while extranasal polypectomy (Caldwell Luc procedures) occurred in 8 (1.3\%). Less common sinonasal procedures were $3(0.5 \%)$ rhinoplasty, $3(0.5 \%)$ nasal cautherization, $3(0.5 \%)$ reduction of nasal bone fracture and $4(0.5 \%)$ suturing of lacerations. This is revealed in Table 6. Complications occurred in sinonasal surgeries in 64 (10.3\%). Main complication of sinonasal procedures in this study was wound infection in 18 (2.9\%). Other documented complication were recurrence in 16 (2.6\%) and epistaxis in 14 (2.3\%). Uncommon complication sin this study included septal perforation and adhesion in $1(0.2 \%)$ and $2(0.3 \%)$ respectively. This is shown in Figure 3. In this study, $65(10.5 \%)$ of the patients were referred to other center for further investigation and treatment. Main limitation and indication for referral were surgical facilities, chemoradiotherapy and diagnostic equipment in 5 (0.8\%), $6(1.0 \%)$ and $41(6.6 \%)$ respectively. Endoscopic sinus surgery was responsible for $4(0.6 \%)$ referral. Patient financial constraints in 28 (4.5\%) leads to delayed surgery. This is illustrated in Figure 4. In this study, 473 (76.2\%) of the patients and their parents were satisfied with the sinonasal surgeries. Revision sinonasal surgeries were offered in $4(0.6 \%)$. We recorded $14(2.3 \%)$ patients' loss to follow up. Surgical failure was noted in $12(1.9 \%)$ patients. Patient in $6(0.6 \%)$ was referral for sinonasal surgery in other center. Referral in $3(0.5 \%)$ was for family support in other center. This is illustrated in Table 6.

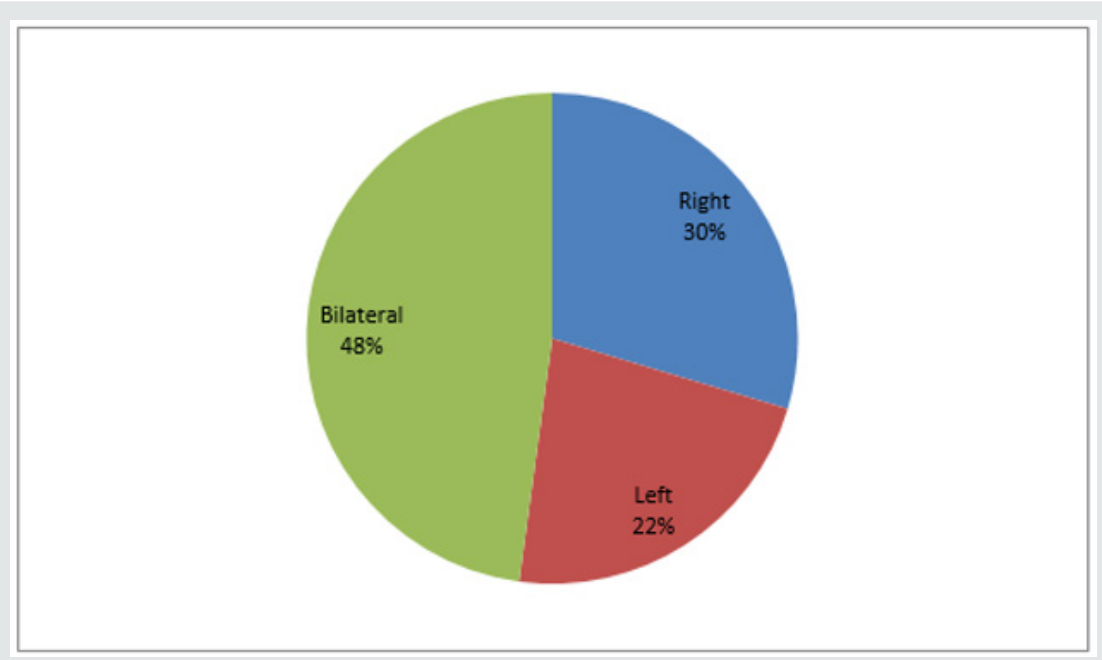

Figure 1: Coronal CT imaging. In hypotympanun the foreign body is visualized (A). 


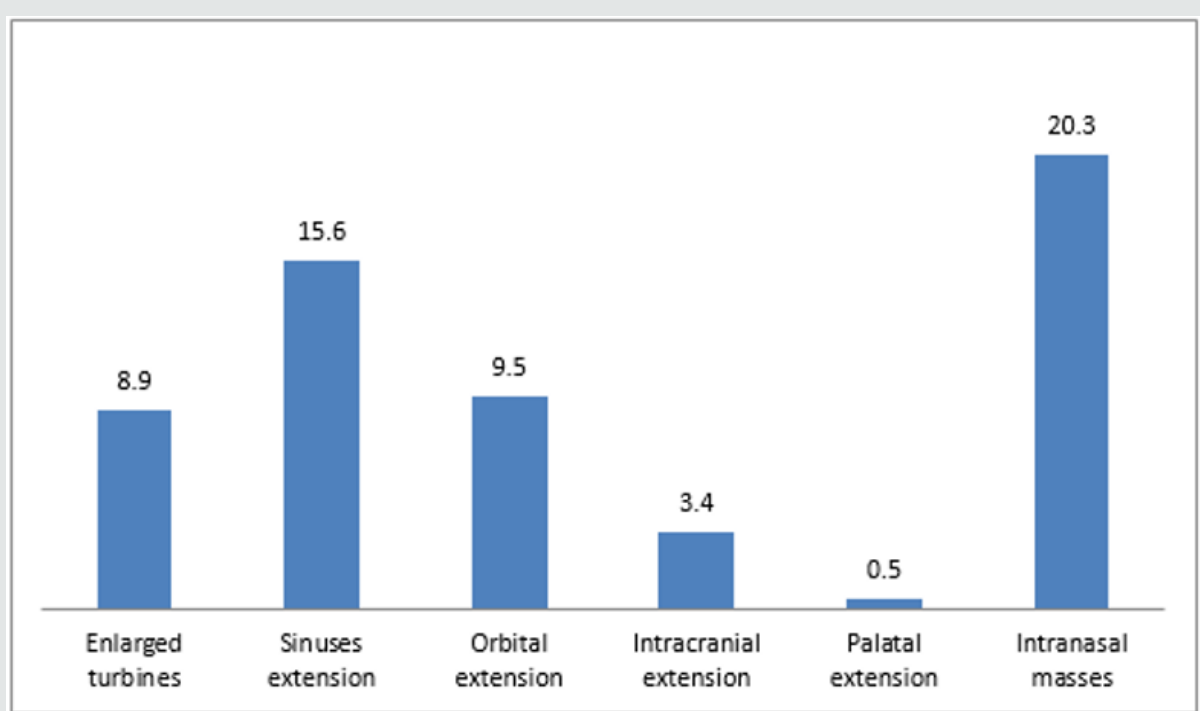

Figure 2: CT Scan findings among patients.

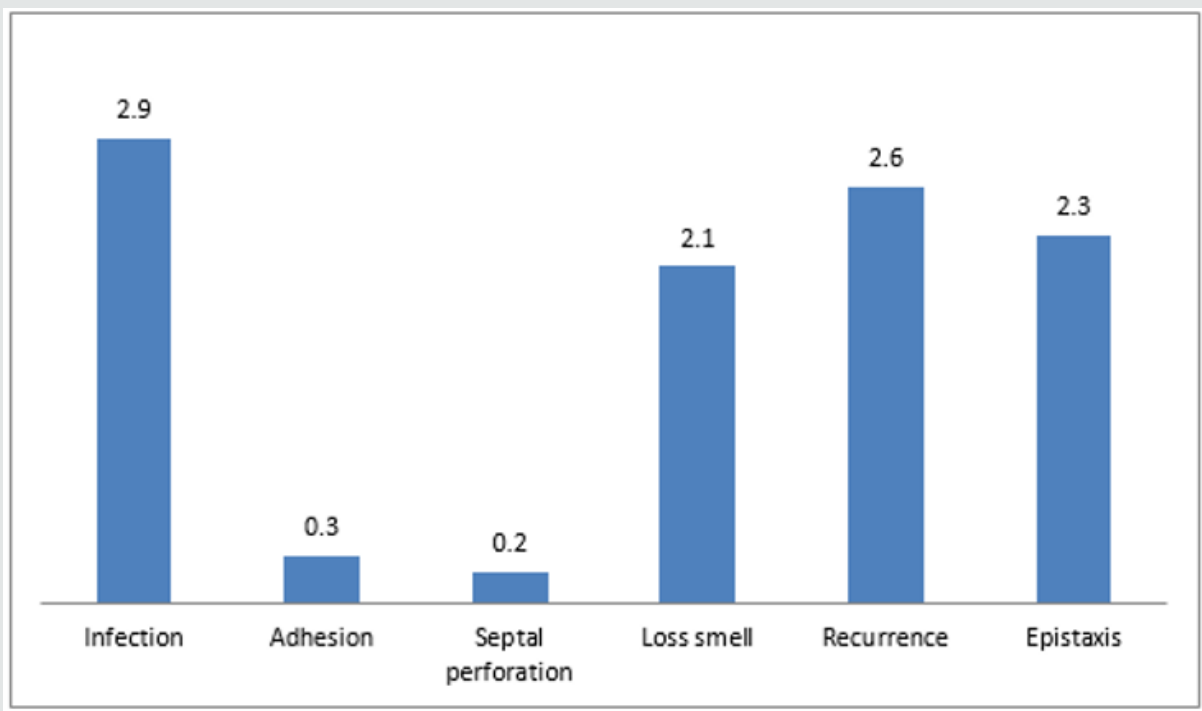

Figure 3: Complications among the patients.

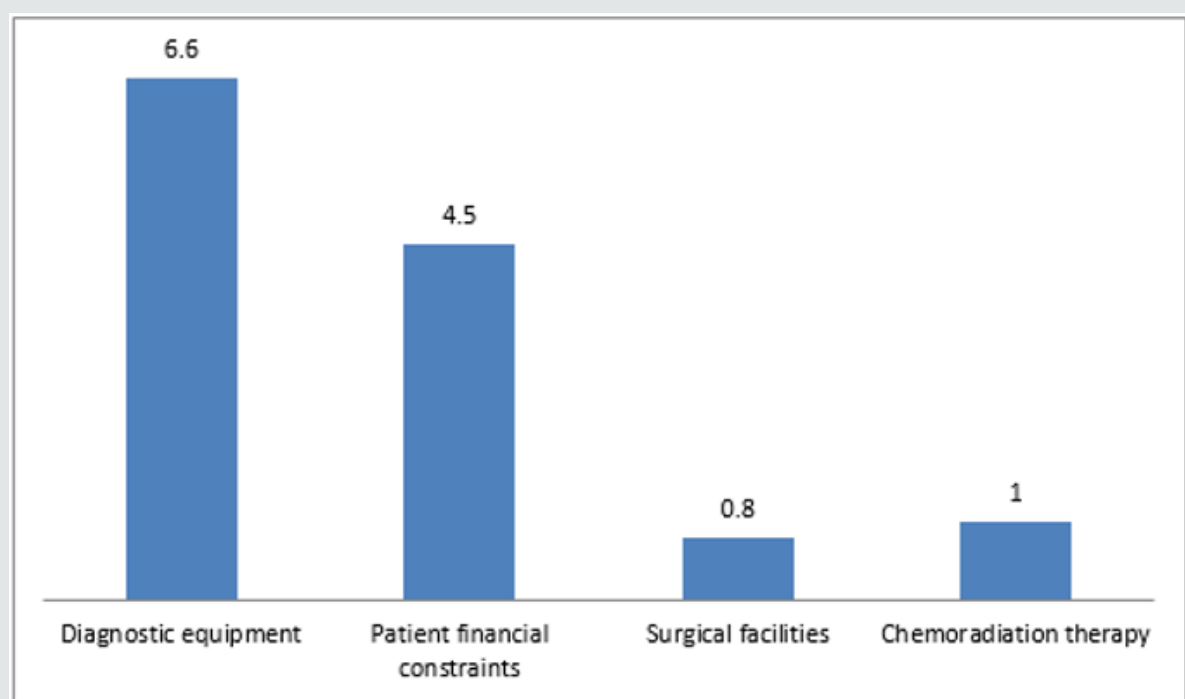

Figure 4: Limitation and indication for referral among the patients. 
Table 4: Main clinical features among patients.

\begin{tabular}{|c|c|c|}
\hline Characteristics of surgery & Number & Percentage (\%) \\
\hline \multicolumn{3}{|c|}{ Types } \\
\hline Major & 182 & 29.3 \\
\hline Intermediate & 17 & 2.7 \\
\hline Minor & 8 & 1.3 \\
\hline \multicolumn{3}{|c|}{ Form } \\
\hline Emergency & 376 & 60.5 \\
\hline Elective & 245 & 39.5 \\
\hline \multicolumn{3}{|c|}{ Location } \\
\hline Clinic & 414 & 66.7 \\
\hline Theatre & 207 & 33.3 \\
\hline
\end{tabular}

Table 5: Diagnosis and indications for surgeries among patients.

\begin{tabular}{|c|c|c|}
\hline Diagnosis & Number & Percentage (\%) \\
\hline Foreign body impaction & 238 & 38.3 \\
\hline Sinonasal injuries & 29 & 4.7 \\
\hline Sinonasal masses & 6 & 1 \\
\hline $\begin{array}{c}\text { Nasal Septal abscess/ } \\
\text { Haematoma }\end{array}$ & 11 & 1.8 \\
\hline Rhinosinusitis & 248 & 39.9 \\
\hline Epistaxis (idiopathic) & 6 & 1 \\
\hline Ethmoidal polyps & 56 & 9 \\
\hline Antrochoanal polyp & 11 & 1.8 \\
\hline Fungal mass & 4 & 0.6 \\
\hline Frontoethmoidal mucocele & 3 & 0.5 \\
\hline Nasolabial cyst & 2 & 0.3 \\
\hline Inverted papilloma & 7 & 1.1 \\
\hline
\end{tabular}

Table 6: Procedures/Surgeries among patients.

\begin{tabular}{|c|c|c|}
\hline $\begin{array}{c}\text { Sinonasal Procedures/ } \\
\text { Surgeries }\end{array}$ & Number & Percentage (\%) \\
\hline Nasal toileting/clearance & 46 & 7.4 \\
\hline Wound dressing & 9 & 1.4 \\
\hline Rhinoplasty & 3 & 0.5 \\
\hline Foreign body removal & 238 & 38.3 \\
\hline Antral washout (lavage) & 61 & 9.8 \\
\hline Nasal Septal abscess I and D & 12 & 1.9 \\
\hline Nasal cautheterization & 3 & 0.5 \\
\hline Nasal packing & 58 & 9.3 \\
\hline Reduction of nasal fractures & 3 & 0.5 \\
\hline Polypectomy & 67 & 10.8 \\
\hline Partial turbinectomy & 51 & 8.2 \\
\hline Intranasal antrostomy & 44 & 7.1 \\
\hline $\begin{array}{c}\text { External fronto- } \\
\text { ethmoidectomy }\end{array}$ & 11 & 1.8 \\
\hline Suturing & 4 & 0.6 \\
\hline Excisional biopsy & 11 & 1.8 \\
\hline
\end{tabular}

\section{Discussion}

Sinonasal diseases is very common among otorhinolaryngology, head and neck diseases that visited our department. Most of these diseases presented late, untreated, poorly treated and usually complicated at presentation. There was high prevalence of surgical interventions due to the disease's stages at presentation. In this study, sociodemographic features affected the pattern of sinonasal surgeries. The procedures were commonest in children and this is associated with high rate of infection, immunity, injuries and insertion of infected objects into head and neck orifices. Sinonasal surgeries are commoner in male than female (Figure 5). This may be due to high rate of infection and outdoor activities such as trauma and hazard in offices in male. Also, high rate of smoking and snuff in male. Due to availability, accessibility, affordability and better informed, urban dwellers had more sinonasal procedures than rural dwellers in this study [17].

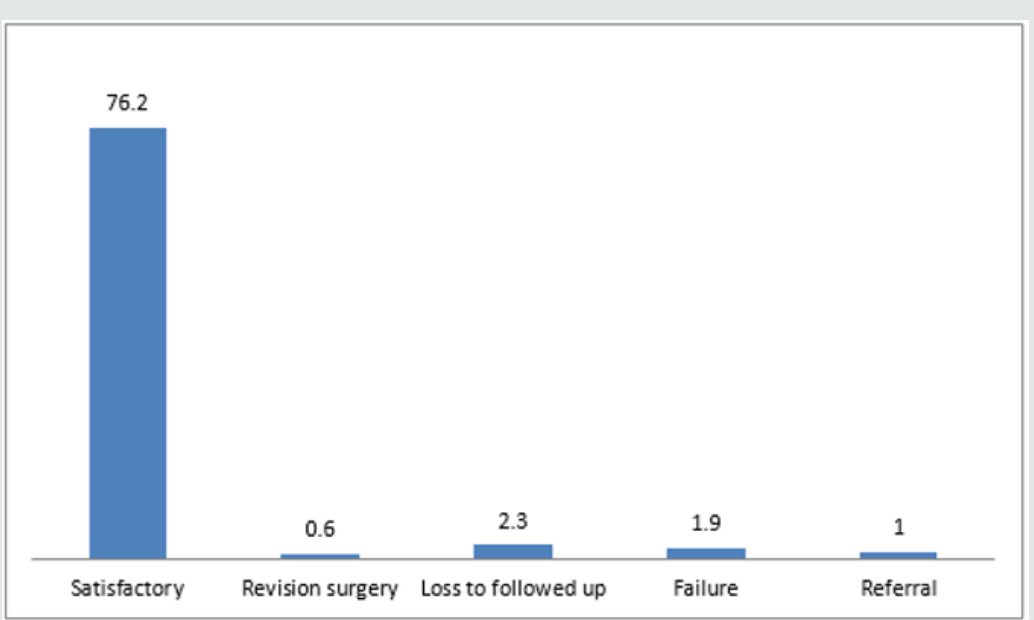

Figure 5: Outcome of the surgeries/procedures among patients. 
Sinonasal diseases in this study presented mainly with nasal blockage, objects in the nose, catarrh/epistaxis and bout of sneezing.18 Most of the patients presented late or with complicated cases. All sinonasal symptoms were assumed to be flu which is selftreated. Most patients or parents wrongly believe it is a household disease, self-limiting, treated at home and does not worth hospital consultation. Common clinical findings in our study were anterior rhinorrhea, reduced nasal patency, nasal foreign body impaction and sinonasal masses $[19,20]$. Unilateral sinonasal disorder were commoner than bilateral this may be because of the aetiology origins of the pathology. Likewise, right sinonasal conditions were commoner than left. Most patients are right handedness with easy picking of right nose. Most patients sleep on the right side with poor venous drainage and accumulation and gravitation of infectious mucous on right nose. Main sinonasal diseases in this study were rhinosinusitis, foreign body impaction and nasal polyps.

In this study, sinonasal diseases are not limited to the nose and sinuses alone irrespective of the aetiopathogenesis. Radiologic imaging is essential to rule out extent of the pathology and adequate preparation for the surgery. Commonest extension was orbit followed by intracranial and palatal extension [21]. Sinonasal Surgeries usually required teamwork with ophthalmologist, neurosurgeon and oral and maxillofacial surgeon depending on the extent of the pathology. Chronic rhinosinusitis with major nasal obstructions in adult is usually secondary to enlarge and obstructive inferior turbinate. In this study, clinic procedures were commoner than theatre surgeries this may be due to inclusion of all cases. There was preponderance of emergency surgery over elective procedures because of self-medications, untrained hand interventions and presentation of complicated cases to our department. Among the theatre cases, commonest surgery was major surgery followed by intermediate and minor surgeries. This is because most of the cases were advanced and extranasal extensions. Commonest procedures were nasal foreign body removal of which majority were performed in outpatient clinic and minority in theatre under general anaesthesia. Polypectomy were performed under general anaesthesia because they are advanced with Intranasal approach commoner than extranasal approach such as Caldwell Luc procedures [22].

Antral washout mainly bilateral was carried out on patients with mucopurulent collection in the maxillary sinuses. Nasal packing was carried out among patients seen with epistaxis mainly secondary to inflammation and trauma. Anterior nasal packing was commoner than posterior packing where chemical cautherization was performed where bleeding point was visualized. Cases of rhinosinusitis were further treated with partial turbinectomy in obstructive turbinate and Intranasal antrostomy to aid antral drainage and ventilation. Nasal toileting/clearance were performed in outpatient clinic among patients mucopurulent and clotted blood in the nasal cavity. Other approach to sinonasal masses in our study was external frontoethmoidectomy or excisional biopsy for histological diagnosis. Depending on the type and form sinonasal injuries surgical interventions in this study were suturing, wound dressing, reduction of nasal bone fracture and rhinoplasty. Nasal septal abscess was drained. No functional endoscopic sinus surgery was performed in our center because endoscope, forceps and other accessories are yet to be procured by hospital management [23]. Associated complications of our sinonasal surgeries were surgical site infection which were treated by antibiotics institutions $[24,25]$. Recurrent tumour in malignancy were referred for chemoradiation therapy. Immediate reactionary haemorrhage which was treated with nasal packing. Temporary loss of olfactory from clotted blood and oedema. Adhesion was released and nasal patency was restored. The septal perforation was asymptomatic, not noticed by patient and being followed up in our out patients clinic. Patients that required are CT Scan referred. Patients with financial constraints were assisted in sourcing for funds and surgery was eventually performed [26]. Patients that required further surgery and chemoradiotherapy were referred to centers where they were available. Majority of the patients were satisfied with the offered procedures. However few cases of revision surgery, referral, loss to followed up and Surgical failure were recorded in this study. This may be due to lower number of major sinonasal surgeries in this study.

\section{Conclusion}

Sinonasal surgeries are still not fully practice despite all the cases and Practicing rhinologist/ otorhinolaryngologist. This is due to limited equipment and adequate funding by policy makers. Provision of adequate surgical facilities will tremendously reduce referral cases and encourage surgical tourism in our center and other developing country.

\section{Funding}

There was no financial support. It is a self sponsored research study.

\section{Competing interests}

All the authors declare that there were no competing interests.

\section{Acknowledgement}

The authors are most grateful to Ekiti state university teaching hospital, the staff and all the patients who participated in this study.

\section{References}

1. Philpott C, Hopkins C, Erskine S, Kumar N, Robertson A, et al. (2015) The burden of revision sinonasal surgery in the UK-data from the Chronic Rhinosinusitis Epidemiology Study (CRES): a cross-sectional study. BMJ Open 5: e006680.

2. Noon E, Hopkins C. (2016) Review article: outcomes in endoscopic sinus surgery. BMC Ear Nose Throat Disord 16:9.

3. Lee S, Lane AP (2011) Chronic Rhinosinusitis as a Multifactorial Inflammatory Disorder. Curr Infect Dis Rep 13(2): 159- 168.

4. Bequignon E, Dupuy L, Zerah Lancner F, Bassinet L, Honoré I, et al. (2019) Critical Evaluation of Sinonasal Disease in 64 Adults with Primary Ciliary Dyskinesia. J Clin Med 8(5): 619.

5. Késmárszky R, Hannington T, Jakkel A, Szabó G. Rhinological (2018) observations during a humanitarian mission in a rural sub-Saharan African setting. European annals of otorhinolaryngology, head and neck diseases 135(5): S99-S102.

6. Kaygusuz A, Haksever M, Akduman D, Aslan S, Sayar Z. (2014) Sinonasal anatomical variations:their relationship with chronic rhinosinusitis and effect on the severity of disease-a computerized tomography assisted 
anatomical and clinical study. Indian J Otolaryngol Head Neck Surg 66(3): 260-266.

7. Handi PS, Patil MN (2017) Evaluation of nose and paranasal sinus disease, anatomical variations by computerized tomography. Int J Otorhinolaryngol Head Neck Surg 3(4): 898-903.

8. Onwuchekwa RC, Alazi N (2017) Computed tomography anatomy of the paranasal sinuses and anatomical variants of clinical relevants in Nigerian adults. Egyptian Journal of Ear, Nose, Throat and Allied Sciences 18(1): 31-38.

9. Calus L, Bruaene NV, Bosteels C Dejonckheere S, Zele TV, et al (2019). Twelve-year follow-up study after endoscopic sinus surgery in patients with chronic rhinosinusitis with nasal polyposis. Clin Transl Allergy 9: 30.

10. Khanna A, Sama (2019) A Managing Complications and Revisions in Sinus Surgery. Current Otorhinolaryngology Reports 7(1): 79-86.

11. Lasisi AO, Adeosun AA (2007) Traditional open surgery for advanced benign nasal tumours in an era of endoscopy: review of 38 cases. African Journal of Health Sciences 14(1): 1-2.

12. Kohanski MA, Reh DD (2013) Granulomatous diseases and chronic sinusitis. American journal of rhinology \& allergy 27(3): S39-S41.

13. Prakash M, JJC (2015) Nasal rhinosporidiosis with an atypical presentation. Journal of pharmacy \& bioallied sciences 7(1): S72.

14. Rizzo S, Giunta AAM, Pennacchi (2015) A Sinonasal and rhinopharyngeal solitary fibrous tumour: a case report and review of the literature. Acta Otorhinolaryngologica Italica 35(6): 455.

15. Mertz LE, Divekar R, Rank MA (2019) Managing Frontal Sinusitis from Systemic Inflammatory Disease. Frontal Sinus Surgery 273-310.

16. Bush CM, Jang DW, Champagne JP, Kountakis SE (2013) Epidemiologic factors and surgical outcomes in patients with nasal polyposis and asthma. ORL 75(6): 320-324.
17. Adegbiji WA, Aremu SK, Lasisi AO (2017) Patients Barrier to Ear, Nose and Throat Surgical Care in Nigeria. American Scientific Research Journal for Engineering, Technology, and Sciences (ASRJETS) 32(1): 96-104.

18. Alabi BS, Afolabi OA, Omokanye HK, Dunmade AD, Ayodele SO (2017) Clinical Presentation and Outcome of Sinonasal Tumors in a Nigerian Tertiary Hospital - 6-year Review. Niger Med J 58(3): 92-95.

19. Adegbiji WA, Aremu SK, Akanbi GO, Omotayo JA (2019) Clinicoepidemiological Presentation of Sinonasal Mass in A Nigerian Tertiary Health Care Centre. Int J Biomed Sci 15(3): 84-90.

20. Adegbiji WA, Olajide GT, Olatoke F, Oyebanji AO, Nwawolo CC (2018) Sociodemographic Profile and Pattern of Sinonasal Injuries at the Ekiti State University Teaching Hospital, Ado-Ekiti, South-West Nigeria. Nigerian Journal of Family Practice 9(3): 25-31.

21. Neel GS, Nagel TH, Hoxworth JM, Lal D (2017) Management of orbital involvement in sinonasal and ventral skull base malignancies. Otolaryngologic Clinics of North America 50(2): 347-364.

22. Adoga A, Nimkur T, Adekwu A, Maan N (2009) An audit of otorhinolaryngological practice in a Nigerian teaching hospital. Internet J Otorhinolaryngol 9(1): 1-4.

23. Onotai LO, Mbalaso OC (2014) Rhinologic Surgeries in The University of Port Harcourt Teaching Hospital: A 5 Years Retrospective Analysis. Gazette of Medicine 3(1): 241-245.

24. Adriaensen GFJPM, Lim KH, Georgalas C, Reinartz SM, Fokkens WJ (2016) Challenges in the management of inverted papilloma: a review of 72 revision cases. The Laryngoscope 126(2): 322-328.

25. Haruna S (2012) Investigation of revision surgery for chronic sinusitis. Practica Oto-Rhino-Laryngologica 105(10): 899-909.

26. Ogunleye AO, Nwaorgu OG, Lasisi AO (2001) Complications of sinusitis in Ibandan, Nigeria. West Afr J Med 20: 98-101.

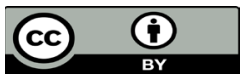

This work is licensed under Creative Commons Attribution 4.0 License

To Submit Your Article Click Here: Submit Article

DOI: $10.32474 /$ SJO.2019.03.000168

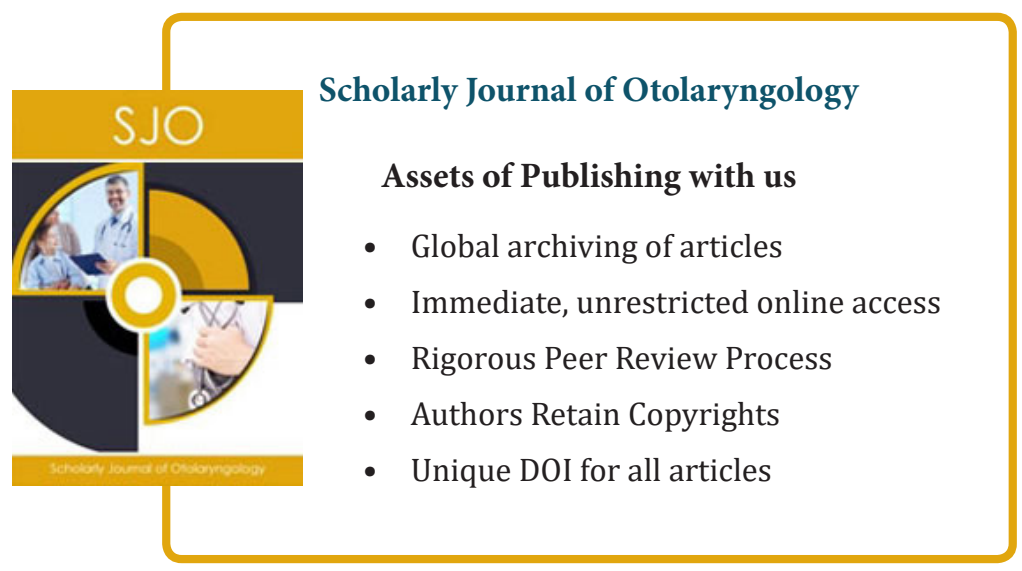

